\title{
Recurrent osteomyelitis of the mandible in osteopetrosis: a common complication of an uncommon disease
}

\author{
Anjali Saigal, ${ }^{1}$ Maragathavalli Gopal, ${ }^{2}$ Neeta Mohanty, ${ }^{3}$ Satya Ranjan Misra ${ }^{4}$
}

${ }^{1}$ Department of Oral Medicine \& Radiology, Dasmesh Institute of Research \& Dental Sciences, Faridkot, Punjab, India

${ }^{2}$ Department of Oral Medicine \& Radiology, Saveetha Dental College \& Hospitals, Chennai, Tamil Nadu, India

${ }^{3}$ Department of Oral Pathology \& Microbiology, Institute of Dental Sciences, Siksha 0 Anusandhan University, Bhubaneswar, Odisha

${ }^{4}$ Department of Oral Medicine \& Radiology, Institute of Dental Sciences, Siksha 0 Anusandhan University, Bhubaneswar, Odisha

\section{Correspondence to} Professor Neeta Mohanty, drneeta2014@gmail.com

Accepted 8 May 2015
CrossMark

To cite: Saigal A, Gopal $M_{\text {, }}$ Mohanty N, et al. BMJ Case Rep Published online: [please include Day Month Year] doi:10.1136/bcr-2014208974

\section{DESCRIPTION}

Osteopetrosis is a congenital disease characterised by overtly dense bone with obliteration of marrow spaces, owing to defective osteoclast function, resulting in excessive and defective bone formation. It is rare, having an incidence of 1 in 250000 births. ${ }^{1}$ Diffuse generalised osteosclerosis of bones is seen and serious oral complications such as osteomyelitis with exposed necrotic bone may occur in the jaws. ${ }^{2}$ Ten per cent of osteopetrosis cases develop osteomyelitis that usually involves the mandible. Osteomyelitis of the maxilla is very rare, probably because of the thin cortical bone and rich collateral blood supply. Osteopetrotic bones lack a bone marrow cavity, fail to resist normal physical loads, and are vulnerable for fractures due to lack of remodelling. ${ }^{1}$ Osteopetrosis is generally diagnosed through skeletal radiographs in which there is increased radiodensity and hence the name 'Marble bone disease'. ${ }^{3}$ Dentists should be aware of the disease because tooth extraction in such patients results in impaired wound healing with recurrent, recalcitrant osteomyelitis.

A 40-year-old man reported with an 8-month history of pain and pus discharge from the right side of his face. History revealed that he had undergone extraction of carious mandibular molar teeth 3 years prior, following which he had recurrent pus discharge, pain and swelling. Since the extraction site did not heal and the patient experienced pain, he subsequently underwent extraction of all his mandibular teeth within 2 years. Even after

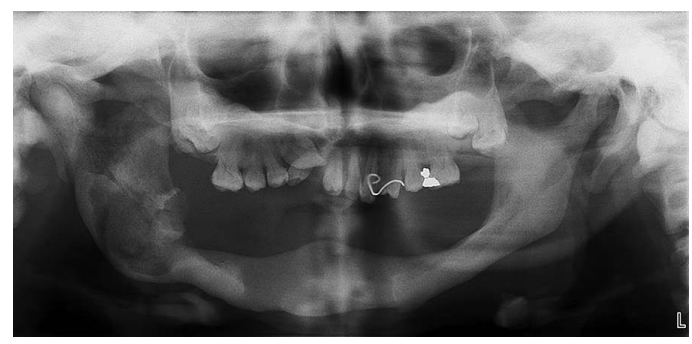

Figure 2 Panoramic radiograph showing diffuse osteosclerosis of the maxilla and with indistinct trabeculae and a 'moth eaten' appearance of the right ramus and angle of the mandible with evidence of a fracture malunion.

extraction of all mandibular teeth there was pus discharge and mandibular fracture. The patient had hip bone fracture 6 years earlier. There was no history of drug use or any other disease, and his personal and family histories were unremarkable.

A diffuse, firm and tender swelling was seen on the right body of the mandible, with two pus discharging sinuses. Intraorally, a single diffuse swelling was seen on the right mandibular alveolus obliterating the buccal sulcus, firm in consistency and slightly tender with discharge of pus on palpation (figure 1). A panoramic radiograph revealed diffuse osteosclerosis of the maxilla with indistinct trabeculae and marrow spaces. A 'moth eaten' appearance of the right ramus and angle of the mandible with evidence of a fracture malunion was
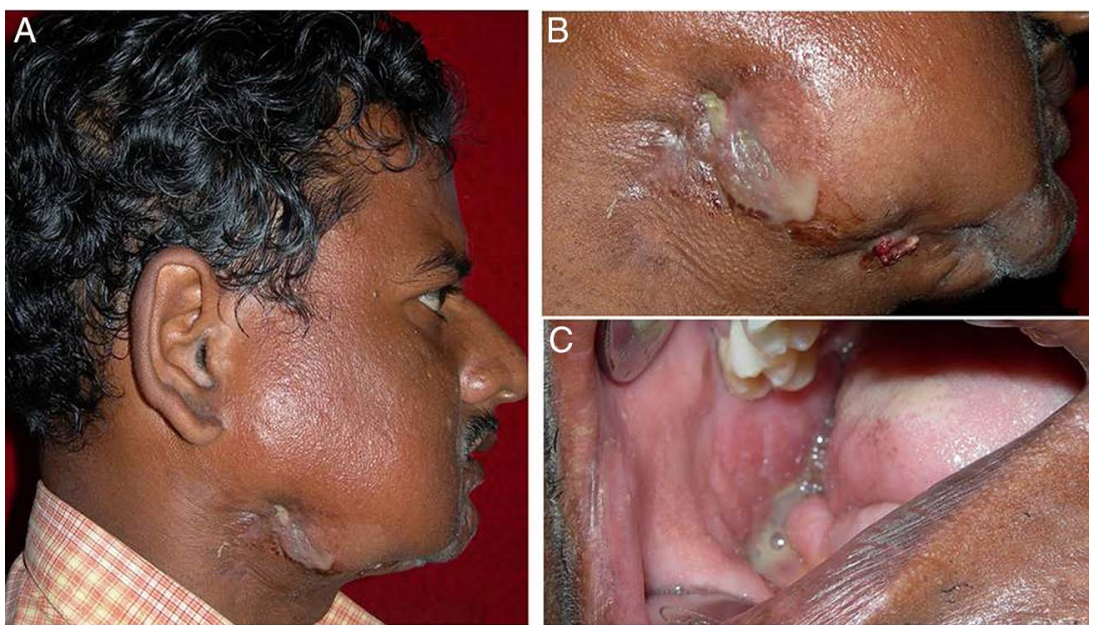

Figure 1 A 40-year-old man with pus discharging sinuses present on the right side of the face (A); multiple pus discharging sinuses on the right parasymphysis and body of mandible with exposed denuded bone (B) and intraorally, pus discharge from the buccal sulcus (C). 

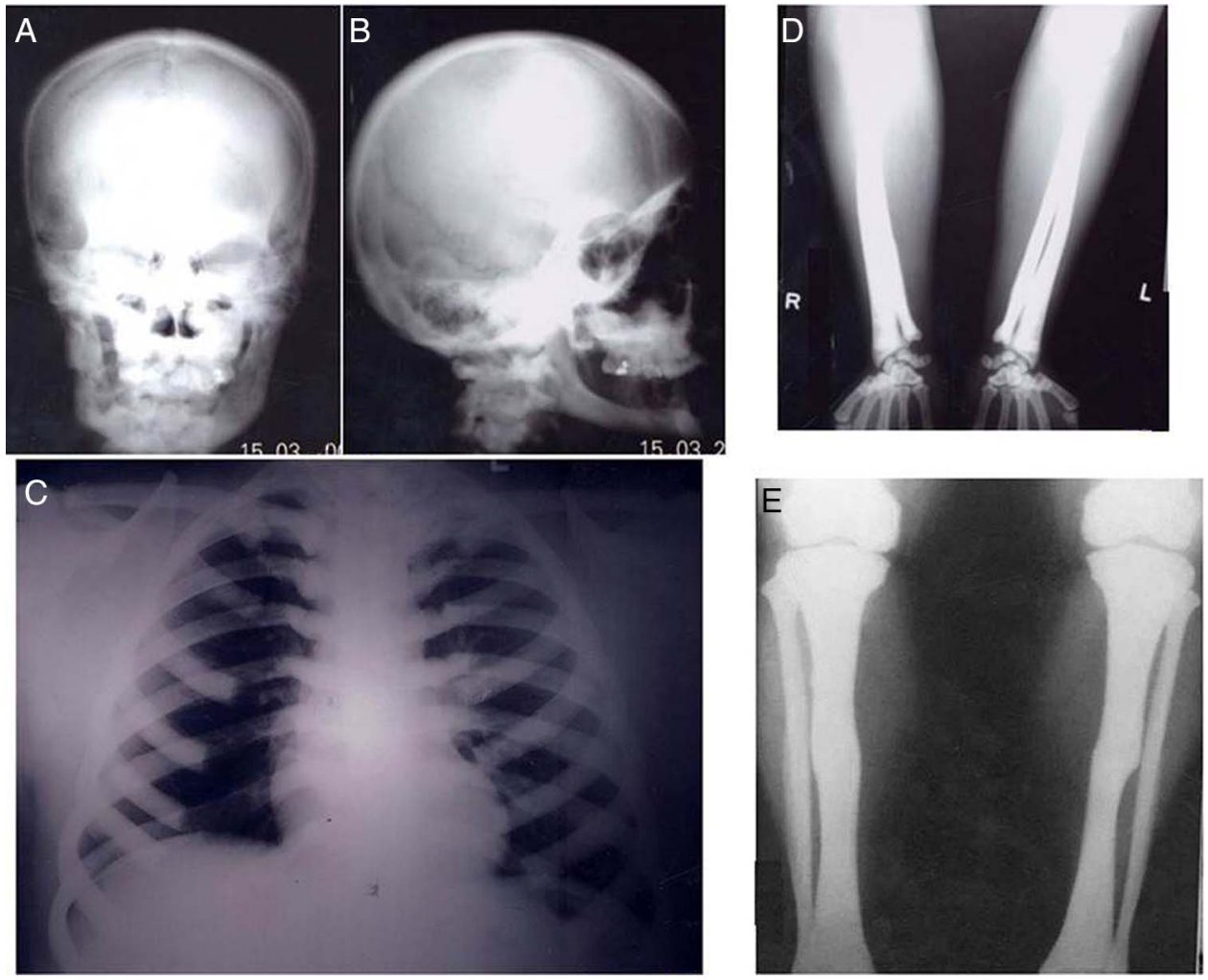

Figure 3 Posteroanterior (A) and lateral (B) skull radiographs, chest radiograph (C), and radiographs of the upper (D) and lower (E) extremities showing generalised increased radiodensity and Erlenmayer flask deformity of the tibia (E).
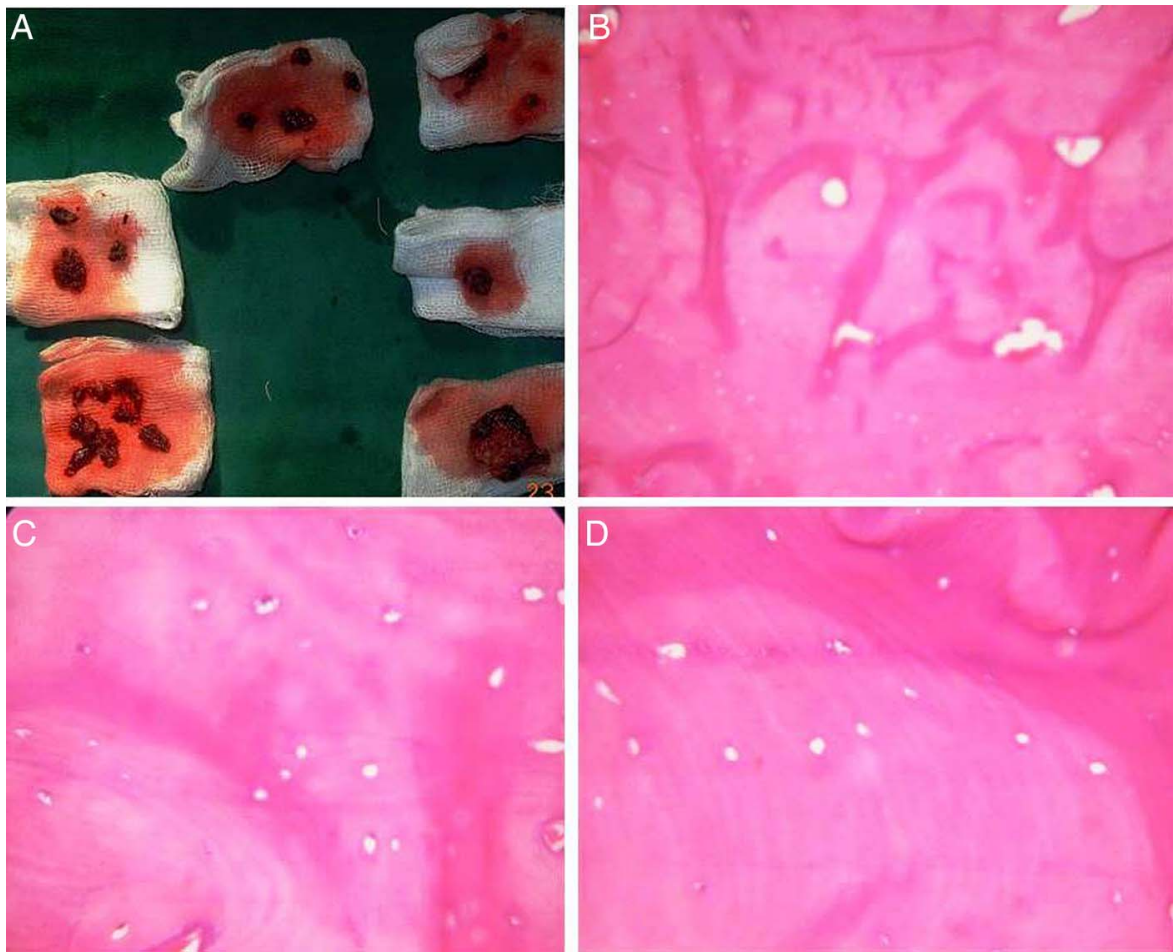

Figure 4 Bony sequestra obtained following curettage. (A) H\&E section showing lamellar bone with numerous lacunae devoid of osteocytes and lack of osteoblastic rimming (original magnification $\times 10$ ); (B) the bony trabaculae also exhibit haematoxyphilic lines with evidence of scanty stroma and areas of vascularity and haemorrhage (original magnification $\times 40 ; C$ and $D$ ). 
observed (figure 2). Radiographs of the skull, chest and limbs also showed diffuse osteosclerosis with an Erlenmayer flask deformity seen in the tibia (figure 3).

Pycnodysostosis, craniometaphyseal dysplasia (Pyle's disease), diaphyseal dysplasia (Camurati-Engelmann-Ribbing disease), osteosclerosis of fluoride poisoning, melorheostosis and osteopathia striata may be considered in the differential diagnosis.

Complete blood count revealed anaemia, neutropaenia and elevated serum acid phosphatase levels. Debridement of the affected site was carried out and bony sequestra were removed

\section{Learning points}

- Benign adult osteopetrosis is a rare bone disease often presenting with an asymptomatic clinical picture.

- Radiographic investigation is essential for accurate diagnosis.

- Osteopetrotic patients are prone to develop infections and are susceptible to jaw bone fractures, hence surgical dental procedures need to be planned to avoid complications.

- Surgical procedures, if required, are to be performed after adequate radiographic and haematological investigations under antibiotic prophylaxis. (figure 4A). The patient was given clindamycin $300 \mathrm{mg}$ tablets two times per day for a week and kept under regular follow-up every 6 months.

Histopathological evaluation revealed lamellar bone with numerous lacunae devoid of osteocytes and osteoblastic rimming and scanty stroma with areas of vascularity (figure 4A-C). A diagnosis of recurrent osteomyelitis in benign adult osteopetrosis was made and the patient was kept on regular follow-up.

Acknowledgements Department of Oral Medicine \& Radiology, Saveetha Dental College \& Hospitals, Chennai, Tamil Nadu, India.

Contributors AS clinically examined the patient and performed all investigations in cooperation with MG and NM. SRM prepared and edited the manuscript.

Competing interests None declared.

Patient consent Obtained.

Provenance and peer review Not commissioned; externally peer reviewed.

\section{REFERENCES}

1 Stark Z, Savarirayan R. Osteopetrosis. Orphanet J Rare Dis 2009:4:5.

2 Infante-Cossio P, Gonzalez-Perez LM, Martinez-de-Fuentes R, et al. Maxillomandibular osteomyelitis associated with osteopetrosis. J Craniofac Surg 2014;25:e79-82.

3 Lam DK, Sándor GK, Holmes HI, et al. Marble bone disease: a review of osteopetrosis and its oral health implications for dentists. J Can Dent Assoc 2007;73:839-43.

Copyright 2015 BMJ Publishing Group. All rights reserved. For permission to reuse any of this content visit http://group.bmj.com/group/rights-licensing/permissions.

BMJ Case Report Fellows may re-use this article for personal use and teaching without any further permission.

Become a Fellow of BMJ Case Reports today and you can:

- Submit as many cases as you like

- Enjoy fast sympathetic peer review and rapid publication of accepted articles

- Access all the published articles

- Re-use any of the published material for personal use and teaching without further permission

For information on Institutional Fellowships contact consortiasales@bmjgroup.com

Visit casereports.bmj.com for more articles like this and to become a Fellow 